O R R I G I N A L

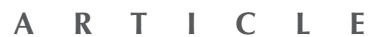

FY Cheung 張寬耀

KC Leung 梁廣泉

Roger KC Ngan 顏繼昌

\title{
Docetaxel chemotherapy for Chinese patients with castrate-resistant prostate cancer
}

Objective To determine the effectiveness and toxicity of docetaxel for Chinese patients with castrate-resistant prostate cancer in a local Hong Kong hospital.

Design Case series.

Setting A tertiary cancer centre in Hong Kong.

Patients In all, 39 castrate-resistant prostate cancer patients were treated with 3 -weekly docetaxel at $75 \mathrm{mg} / \mathrm{m}^{2}$ and prednisolone $10 \mathrm{mg}$ daily between January 2006 and December 2011 in Queen Elizabeth Hospital.

Main outcome measures Prostate-specific antigen control rate, pain control rate, progression-free survival, overall survival, and complication rates.

Results The prostate-specific antigen response rate was 36\%, and 27 (69\%) of the patients had improved pain control after chemotherapy. The median progression-free survival, cancer-specific survival, and overall survival was 7.8 (95\% confidence interval, $4.9-10.8)$ months, 13.0 (95\% confidence interval, 9.6-16.3) months, and 12.2 (95\% confidence interval, 9.3-15.1) months, respectively. The grade 3 anaemia and thrombocytopenia rates were $5 \%$, and the neutropenic fever rate was $8 \%$.

Conclusions Chemotherapy with docetaxel at a dose of $75 \mathrm{mg} / \mathrm{m}^{2}$ given once every 3 weeks together with daily prednisolone is well tolerated in Chinese and can offer good symptom palliation in suitable patients with castrate-resistant prostate cancer.

New knowledge added by this study

- Clinical outcomes are good and toxicity of docetaxel chemotherapy is minimal for Chinese castrate-resistant prostate cancer (CRPC) patients.

Implications for clinical practice or policy

- Docetaxel and prednisolone can be used as first-line treatment for Chinese CRPC patients.

Key words

Androgen antagonists; Drug therapy; Prostate neoplasms; Survival

Hong Kong Med J 2013;19:237-41 DOI: $10.12809 / \mathrm{hkmj} 133804$

Department of Clinical Oncology, Queen Elizabeth Hospital, 30 Gascoigne Road, Kowloon, Hong Kong FY Cheung, FRCR, FHKAM (Radiology) KC Leung, FRCR, FHKAM (Radiology) RKC Ngan, FRCR, FHKAM (Radiology)

Correspondence to: Dr FY Cheung Email: cheungfy@ha.org.hk

\section{Introduction}

In Hong Kong men, prostate cancer was the third most common cancer and the fifth most common cancer causing death in 2009. ${ }^{1}$ The median age at diagnosis was 73 years. The incidence of prostate cancer is increasing worldwide, especially in developed countries. Early disease can be treated by local therapy, such as surgery or radiotherapy, but hormonal therapy is useful in controlling advanced and metastatic disease. However, androgen blockage usually ceases to control the disease after about 2 years and tumour can grow even with the androgen levels that prevail after castration. Nevertheless, castrate-resistant prostate cancer (CRPC) can be treated with chemotherapy with the goal of relieving symptoms and prolonging survival.

In 2004, the results of two randomised trials (TAX 327 and the Southwest Oncology Group 99-16) were published, ${ }^{2,3}$ and both revealed significant survival benefits for men treated with docetaxel. In TAX 327, ${ }^{2}$ docetaxel $\left(75 \mathrm{mg} / \mathrm{m}^{2}\right)$ every 3 weeks, and docetaxel $\left(30 \mathrm{mg} / \mathrm{m}^{2}\right)$ weekly for 5 weeks out of 6 , were compared with mitoxantrone $\left(12 \mathrm{mg} / \mathrm{m}^{2}\right)$ every 3 weeks, each accompanied with prednisolone $5 \mathrm{mg}$ twice daily. The results showed significantly longer overall survival for men treated with 3-weekly docetaxel, which also conferred a higher probability of reducing pain and improving quality of life. ${ }^{2}$ Since 


\section{去勢難治性前列腺癌華籍患者的多西紫杉醇化療}

目的 探討香港一所醫院中多西紫杉醇對去勢難治性前列腺 癌華籍患者的成效和毒性。

設計 病例系列。

安排 香港一所提供第三層醫療的癌症中心。

患者 2006年1月至2011年12月期間在伊利沙伯醫院接受每 三週一次的多西紫杉醇化療（劑量為 $75 \mathrm{mg} / \mathrm{m}^{2}$ ) ，以 及每日口服潑尼松龍（劑量為10 mg) 的39名去勢難 治性前列腺癌患者。

主要結果測量 前列腺特定抗原的控制率、疼痛控制率、無進展生存 期、總存活期和併發症比率。

結果 前列腺特異性抗原的反應率為36\%，27名（69\%）患 者接受化療後疼痛控制有改善。無進展生存期、腫瘤 特異性存活期和總存活期分別為 7.8個月（95\%置信 區間：4.9-10.8）、13.0個月（95\%置信區間：9.616.3 ) 和 12.2個月（95\%置信區間：9.3-15.1）。三 級貧血和血小板減少症比率均為 $5 \%$, 另中性粒細胞 減少性發熱比率為 $8 \%$ 。

結論 去勢難治性前列腺癌華籍患者接受每三週一次劑量為 $75 \mathrm{mg} / \mathrm{m}^{2}$ 的多西紫杉醇化療, 以及每日口服劑量為 $10 \mathrm{mg}$ 的潑尼松龍的耐受性良好, 並可以為合適的患 者提供良好的症狀緩解。

the publication of these two studies, docetaxel has become established as first-line treatment for CRPC patients considered suitable for chemotherapy.

Although docetaxel is widely used, there are few reports on clinical outcomes in Chinese CRPC patients. The purpose of the current study was to review the role of docetaxel in the largest cancer centre in Hong Kong. The study also examined this drug's treatment toxicities, and symptom control.

\section{Methods}

A retrospective analysis was performed of all CRPC patients treated with docetaxel $75 \mathrm{mg} / \mathrm{m}^{2} 3$-weekly and daily prednisolone $5 \mathrm{mg}$ twice daily between January 2006 and December 2011. For that purpose, CRPC was defined as progression of disease or elevation of prostate-specific antigen (PSA) level from its baseline value in at least two consecutive blood samples obtained at least 7 days apart. ${ }^{4}$ Antiandrogen therapy was stopped before starting chemotherapy and androgen ablation was continued with luteinising hormone-releasing hormone agonists if bilateral orchidectomy had not been performed. Adequate renal, hepatic, and cardiac function and an Eastern Cooperate Oncology Group (ECOG) performance status score of 0 to 2 were prerequisites for treatment. For patients with rapidly rising PSA levels (doubling time $<3$ months), soft tissue or visceral metastases, or histology showing poorly differentiated carcinoma lacking neuroendocrine features, early chemotherapy intervention was contemplated immediately after antiandrogen failure.

The demographic data, chemotherapy dose intensity, PSA responses, pain control, treatment toxicities, progression-free survival, cancer-specific survival, and overall survival in the relevant patients were reviewed and analysed. A PSA response was defined as decline in serum level of more than $50 \%$. Pain control was determined retrospectively from clinical notes after reviewing the amount of analgesic consumption and symptom intensity descriptions. Complete cessation of analgesic consumption plus having "no pain" was defined as complete resolution of pain. Decreased analgesic consumption associated with "less pain" was defined as improvement in pain control. No quality-of-life data or other questionnaires for pain assessment were used.

Kaplan-Meier curves were used to estimate progression-free and overall survival rates. Survival was defined from the date of first docetaxel use to the date of death from any cause or censored at the date of the last follow-up visit. Progression-free survival was defined as the time from first docetaxel treatment to the first occurrence of clinical or PSA progression or death from any cause.

Haematological complications were retrospectively graded using the United States Department of Health and Human Services Common Terminology Criteria for Adverse Events version 4.0 (CTCAE). The number of patients who complained of systemic side-effect such as malaise and ankle oedema was retrieved from clinical notes, but no detailed grading was undertaken. Statistical calculations were performed using the Statistical Package for the Social Sciences (Windows version 15.0; SPSS Inc, Chicago [IL], US). All tests were two-sided and $\mathrm{P}$ values of $<0.05$ were considered statistically significant.

\section{Results}

In all, 39 patients were included for assessment during the study period. The median age at the start of chemotherapy was 70 (range, 53-82) years. In all, 38 patients had a prior histological diagnosis of adenocarcinoma of the prostate; 29 of them had a median total Gleason score of 7 (range, 5-10), and 32 had metastatic disease on presentation. The median time to the start of chemotherapy after the diagnosis was 3 (range, 1-9) years. The median PSA level at the time of starting chemotherapy was 229 (range, 1-4712) $\mu \mathrm{g} / \mathrm{L}$. The median follow-up period from 
starting chemotherapy was 10 (range, 1-55) months. All except two patients had a performance status of ECOG 1 at the initiation of chemotherapy. Relevant data are summarised in Table 1.

In all, 14 patients stopped chemotherapy before the planned 6 cycles, 12 had more than 6 cycles, and the remaining 13 completed the 6 cycles. Among the 14 patients, chemotherapy was stopped in seven (18\% of the 39 patients) due to disease progression, and in five due to treatment toxicity or exacerbation of concurrent medical illnesses. One patient died of an unknown cause during chemotherapy, and another stopped chemotherapy after the third cycle for financial reasons. There were four patients in whom there was a 75 to $80 \%$ docetaxel dosage reduction; in one it was related to non-neutropenic sepsis and in three others because of extensive bone metastases.

The haematological toxicity was unexpectedly mild. In all, CTCAE grade 3 anaemia treated by transfusion was observed in only two $(5 \%)$ of the patients, and another two (5\%) had CTCAE grade 3 thrombocytopenia but did not receive any platelet transfusion. Without routine growth factor support, chemotherapy was complicated with neutropenic sepsis in three $(8 \%)$ of the patients. The most common chemotherapy-related constitutional symptoms were malaise, nausea, and vomiting. Four $(10 \%)$ of the patients complained of malaise and two (5\%) complained of bilateral ankle oedema. There was no recorded severe treatment-related neurotoxicity.

The PSA response rate was $36 \%$ (14/39). The median drop in PSA level was $81 \mu \mathrm{g} / \mathrm{L}$. In $27(69 \%)$ of the patients, pain control improved after chemotherapy, and 15 (38\%) of them ceased taking all analgesics. In four of the patients, groin, axillary or supraclavicular lymph node metastases underwent complete remission after chemotherapy. Chemotherapy toxicities encountered and responses to treatment are summarised in Table 2.

With longer follow-up, 29 patients in this treatment cohort had disease progression at the time of analysis. Overall 24 patients had died, 20 because of prostate cancer and four (10\%) from another medical illness or unknown causes. The median progressionfree survival was 7.8 (95\% confidence interval [CI], 4.9-10.8) months, the median cancer-specific survival was $13.0(95 \% \mathrm{Cl}, 9.6-16.3)$ months, and the median overall survival was $12.2(95 \% \mathrm{Cl}, 9.3-15.1)$ months. Progression-free survival, cancer-specific survival, and overall survival curves are shown in the Figure. Univariate analysis of progression-free survival, cancer-specific survival, and overall survival did not reveal any pre-chemotherapy predictors of significance, with respect to age, performing status, Gleason score, presence of visceral metastasis, initial presentation of pain, initial haemoglobin level, and initial line of therapy.

\begin{tabular}{lc} 
TABLE I. Patient characteristics & \\
\hline Characteristic & $\begin{array}{c}\text { Median (range) or } \\
\text { No. (\%) of cases }\end{array}$ \\
\hline Age at chemotherapy (years) & $70(53-82)$ \\
With histological diagnosis & $38(97.4 \%)$ \\
With Gleason score & $29(74.4 \%)$ \\
Gleason score & $7(5-10)$ \\
Time from diagnosis to chemotherapy (years) & $3(1-9)$ \\
\hline PSA* at chemotherapy start $(\mu g / L)$ & $229(1-4712)$ \\
Follow-up from start of chemotherapy (months) & $10(1-55)$ \\
\hline
\end{tabular}

* PSA denotes prostate-specific antigen

TABLE 2. Summary of toxicities and responses

\begin{tabular}{lc}
\hline Toxicity/response & No. (\%) of patients ${ }^{\star}$ \\
\hline Haematological toxicities & $2(5)$ \\
\hline Grade 3 anaemia & $3(8)$ \\
\hline Neutropenic sepsis & $2(5)$ \\
\hline Grade 3 thrombocytopenia & \\
Systemic symptoms from treatment & $4(10)$ \\
Malaise & $2(5)$ \\
\hline Ankle oedema & \\
Responses & $14(36)$ \\
\hline PSA ${ }^{\dagger}>50 \%$ decrease & 81 \\
\hline Median PSA reduction $(\mu \mathrm{g} / \mathrm{L})$ & $27(69)$ \\
\hline Decrease in pain & $15(38)$ \\
\hline Analgesic-free & \\
\hline
\end{tabular}

* Except otherwise stated

+ PSA denotes prostate-specific antigen

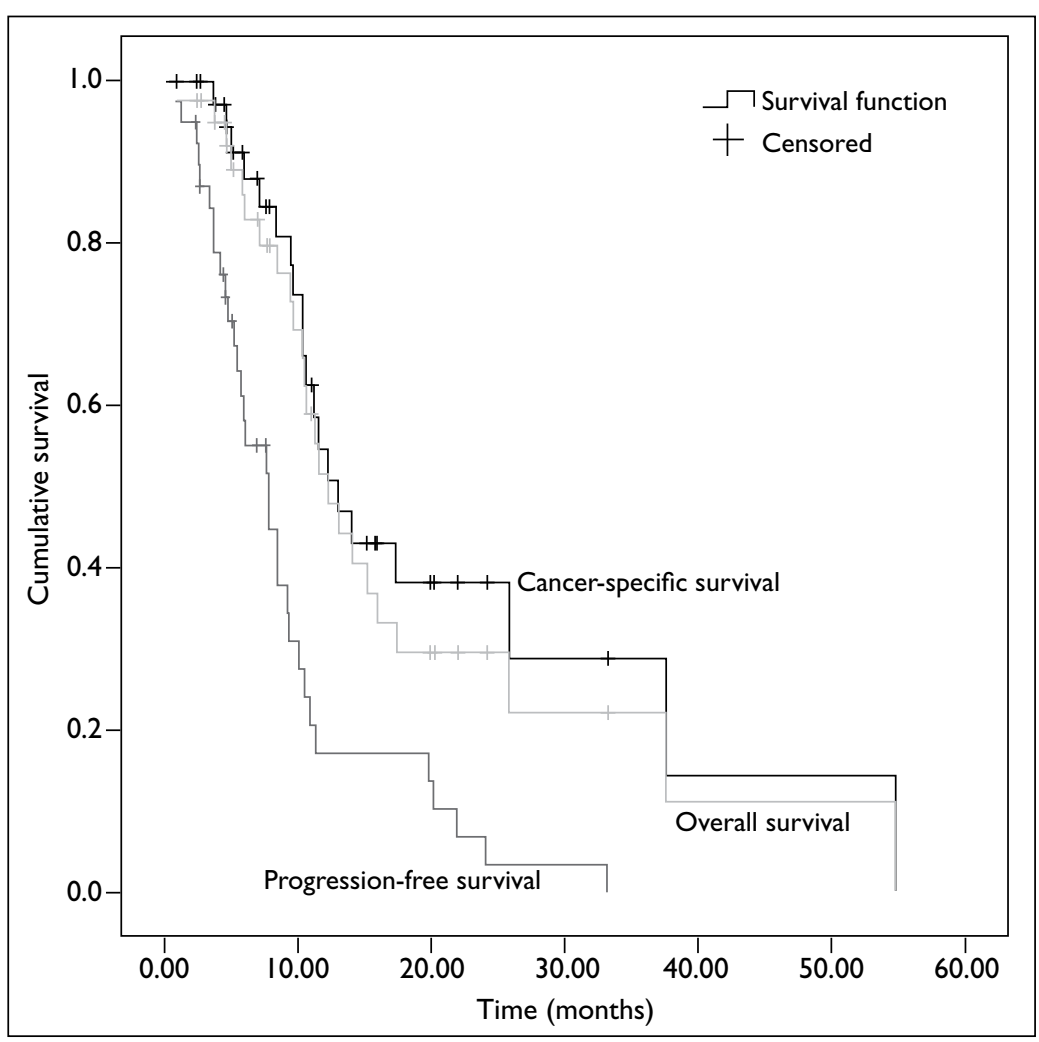

FIG. Progression-free survival, cancer-specific survival, and overall survival curves 
TABLE 3. Summary of treatment outcome of large phase III randomised trials and Queen Elizabeth Hospital (QEH) results*

\begin{tabular}{|c|c|c|c|c|c|}
\hline Study & No. of patients & PSA $>50 \%$ decrease & Decrease in pain & Median survival (months) & TTP or PFS \\
\hline \multicolumn{6}{|l|}{$\operatorname{TAX} 327^{2}$} \\
\hline Mitoxantrone & 337 & $32 \%$ & $22 \%$ & 17 & - \\
\hline Docetaxel 3-weekly & 335 & $45 \%^{\dagger}$ & $35 \%^{\dagger}$ & $19^{\dagger}$ & - \\
\hline Docetaxel weekly & 334 & $48 \%^{\dagger}$ & $31 \%$ & 17 & - \\
\hline \multicolumn{6}{|l|}{ SWOG $99-16^{3}$} \\
\hline Docetaxel/estramustine & 336 & $50 \%^{\dagger}$ & - & $18^{\dagger}$ & 6.3 Months ${ }^{\dagger}$ \\
\hline Mitoxantrone & 338 & $27 \%$ & - & 16 & 3.2 Months \\
\hline \multicolumn{6}{|l|}{ Tannock et $\mathrm{al}^{5}$} \\
\hline Mitoxantrone & 81 & $22 \%$ & $12 \%$ & - & 43 Weeks $^{\dagger}$ \\
\hline Prednisolone & 80 & $33 \%$ & $29 \%$ & - & 18 Weeks \\
\hline \multicolumn{6}{|l|}{ Current study in QEH (2012) } \\
\hline Docetaxel 3-weekly & 39 & $36 \%$ & $69 \%$ & 12 & 7.8 Months \\
\hline
\end{tabular}

* PSA denotes prostate-specific antigen, TTP time to progression, and PFS progression-free survival

+ Statistically significant

\section{Discussion}

This is one of the few reports that demonstrate the benefits of docetaxel and prednisolone in Chinese CRPC patients. The retrospective nature of the analysis may render the assessment of systemic symptoms, symptom control, and side-effects inaccurate. However, the objective nature of the PSA response, as well as progression-free, cancerspecific, and overall survival all suggest treatment effectiveness. Our results are consistent with those of large phase III randomised trials on docetaxel, ${ }^{2,3}$ and indicate greater effectiveness than after mitoxantrone therapy. ${ }^{4}$ The treatment outcomes of these randomised trials and our retrospective analysis are summarised in Table 3.,.$^{2,5}$ While there was no simple explanation for the lower PSA response rate and lower overall survival rate achieved in our series, our patients did have a higher median PSA level at initiation of chemotherapy. This observation appears to be consistent with increased tumour load from metastases than in the randomised studies referred to.

Haematological toxicity, especially neutropenia and neutropenic sepsis, is always a concern with chemotherapy regimens employing docetaxel. Analysis of docetaxel use in Chinese breast cancer patients revealed that neutropenic fever rates ranged from 14 to $21 \%,{ }^{6,7}$ which was higher than the $8 \%$ encountered in our Chinese men with CRPC. One possible explanation could be due to the lower docetaxel doses used in prostate cancer patients.

Due to the limited number of patients included in this retrospective, single-centre analysis, no prognostic factors could be identified. Nevertheless, the study achieved its aims, in that it showed this treatment was effective and well tolerated. A prospective multicentre study is necessary for further prognostic factor analysis.

After the introduction of docetaxel as standard therapy of CRPC patients in 2004, there has been further progress in the treatment of this group of patients. In 2010, sipuleucel-T was approved for use in asymptomatic or minimally symptomatic CRPC patients in the United States. It is also the first immunotherapy agent shown to confer overall survival benefits in selected CRPC patients in a phase III randomised trial. ${ }^{8}$

Since almost all docetaxel-treated CRPC patients progress after treatment, there are still unmet needs to provide second-line therapy when treatment fails. Abiraterone is a selective inhibitor of androgen biosynthesis with the potential to block cytochrome P450 c17 (CYP17). In a phase III randomised trial, when this agent was given with prednisolone, it demonstrated overall survival and progression-free survival benefits in CRPC patients failing docetaxel, when compared to placebo given with prednisolone. ${ }^{9}$ Cabazitaxel is a new semi-synthetic taxane that may overcome the emergence of taxane resistance. In TROPIC, a phase III trial to compare cabazitaxel with mitoxantrone after progression following docetaxel therapy, the former was shown to confer overall and progression-free survival benefits. ${ }^{10}$ These two new agents are not yet readily available in Hong Kong. In our institution, the current management policy for such patients is to rechallenge them with docetaxel and prednisolone if they previously manifested responses, or switch to alternative agents such as 
mitoxantrone or vinorelbine. In one retrospective series, rechallenge with docetaxel was followed by more than a $50 \%$ reduction of PSA levels in more than half the patients. ${ }^{11}$ In docetaxel-resistant patients, the response rate to second-line mitoxantrone treatment was about $20 \% .^{12}$

\section{Conclusion}

Chemotherapy with docetaxel at a dose of $75 \mathrm{mg} / \mathrm{m}^{2}$ given once every 3 weeks together with daily prednisolone is well tolerated in Chinese CRPC patients and can offer good symptom palliation.

\section{References}

1. Hong Kong Cancer Registry, Hospital Authority. Top 10 cancers in 2009. HA website: http://www.ha.org.hk/ cancereg. Accessed 25 Mar 2012.

2. Tannock IF, de Wit R, Berry WR, et al. Docetaxel plus prednisolone or mitoxantrone plus prednisolone for advanced prostate cancer. N Engl J Med 2004;351:1502-12. cross ref

3. Petrylak DP, Tangen CM, Hussain MH, et al. Docetaxel and estramustine compared with mitoxantrone and prednisolone for advanced refractory prostate cancer. $N$ Engl J Med 2004;351:1513-20. cross ref

4. Bubley G), Carducci M, Dahut W, et al. Eligibility and response guidelines for phase II clinical trials in androgenindependent prostate cancer: recommendations from the Prostate-Specific Antigen Working Group. J Clin Oncol 1999; 17:3461-7.

5. Tannock IF, Osoba D, Stockler MR, et al. Chemotherapy with mitoxantrone plus prednisolone or prednisolone alone for symptomatic, hormone-resistant prostate cancer: a Canadian randomized trial with palliative end points. J Clin Oncol 1996;14:1756-64.

6. Yip AY, Chow LW. Clinical experience with docetaxel for Chinese breast cancer patients: haematological profiles. Breast Cancer 2006;13:192-6. cross ref

7. Yau TK, Ng TY, Soong IS, et al. Toxicity of docetaxel plus cyclophosphamide as adjuvant therapy for breast cancer in Chinese patients-the Hong Kong experience. Asia Pac J Clin Oncol 2009;5:123-8. cross ref

8. Kantoff PW, Higano CS, Shore ND, et al. Sipuleucel-T immunotherapy for castration-resistant prostate cancer. $\mathrm{N}$ Engl J Med 2010;363:411-22. cross ref

9. de Bono JS, Logothetis CJ, Molina A, et al. Abiraterone and increased survival in metastatic prostate cancer. $N$ Engl J Med 2011;364:1995-2005. cross ref

10. de Bono JS, Oudard S, Ozguroglu M, et al. Prednisolone plus cabazitaxel or mitoxantrone for metastatic castrationresistant prostate cancer progressing after docetaxel treatment, a randomized open-label trial. Lancet 2010;376:1147-54. cross ref

11. Eymard J, Oudard S, Gravis G, et al. Second-line chemotherapy with docetaxel in men treated with docetaxel-based regimen for metastatic hormone-refractory prostate cancer [abstract]. Proceedings of the ASCO 2007 Prostate Cancer Symposium. 2007 Feb 22-24. 2007: 249.

12. Rosenberg JE, Weinberg VK, Kelly WK, et al. Activity of second line chemotherapy in docetaxel-refractory hormonerefractory prostate cancer patients: randomized phase 2 study of ixabepilone or mitoxantrone and prednisolone. Cancer 2007; 110:556-63. cross ref 